\title{
Héroes frigios, nación y distorsión. La batalla por la supertónica descendida como signo musical en el metal español
}

\author{
Phrygian Heroes, Nation and Distortion. \\ The Battle for the Flatted Second as a \\ Musical Sign in Spanish Heavy Metal
}

El modo frigio, poco habitual en el canon del rock anglosajón, es, sin embargo, un elemento estilístico profusamente empleado en el heavy metal. En especial, la supertónica descendida (b2) ha sido abordada en relación con su apropiación desde la masculinidad en el heavy metal y con su uso en estos repertorios como elemento de tensión y disonancia, en ocasiones vinculado a lo oscuro y a la fatalidad. El presente artículo examina procesos inter/hipertextuales y transfonográficos en torno al modo frigio, al intervalo de segunda menor y a la supertónica descendida en la música metal en España. Se presentan una diversidad de representaciones de esta estructura melódica o armónica, desde imaginarios sobre lo andaluz, español, árabe y flamenco en música que conectan estas estructuras musicales con el exotismo y el orientalismo, hasta su uso como marcador estilístico del metal sin evocaciones territoriales explícitas. Este signo musical, continuamente reapropiado dentro de un entramado complejo de significados presentes en la canción popular grabada de las bandas de metal, conforma un espacio de primer nivel en la enunciación de narrativas patrimoniales diversas. Estos aspectos son vinculados en el artículo a la construcción de discursos en torno a las identidades nacionales en España y la recreación de comunidades imaginadas basadas en mitos históricos y héroes nacionales, desde la exaltación de figuras como la del Cid hasta la evocación del pasado de Al-Ándalus.

Palabras clave: heavy metal español, supertónica descendida, modo frigio, identidad nacional, intertextualidad.

Despite its unusualness in the Anglo-Saxon rock music canon, the Phrygian mode is a stylistic element that is widely used in heavy metal. In particular, the flatted second degree of the scale (supertonic) (b2) has been discussed in relation to its appropriation from masculinity in heavy metal and its use as an element of tension and dissonance in these repertories, sometimes associated with a sinister style and with doom. This article discusses inter/hypertextual and transphonographic processes based around the Phrygian mode, the minor second and the flatted second in heavy metal music in Spain. A variety of representations of this melodic and/or harmonic structure are presented, from imaginaries about the Andalusian, Spanish, Arab and flamenco style in music that connect these musical forms with exoticism and orientalism, to its use as a stylistic marker of heavy metal without explicit territorial evocations. This musical sign, constantly reappropriated within a complex network 
of meanings present in popular songs recorded by heavy-metal bands, constitutes a first level in the enunciation of diverse patrimonial narratives. In this article, these aspects are linked to the construction of discourses around national identities in Spain and the recreation of imagined communities based on historical myths and national heroes, from the exaltation of figures such as El Cid to the evocation of the past of Al Andalus.

Keywords: Spanish heavy metal, flatted second, Phrygian mode, national identity, intertextuality.

En 2007, Arturo Pérez-Reverte dedicaba unas líneas al heavy metal en las cuales, frente a la criminalización mediática que, en ocasiones, se vincula a estas músicas, valoraba positivamente el bagaje cultural que algunas bandas profesaban. Esta visión aprobativa no solo fue celebrada entre foros de aficionados al metal, sino que también ha servido para la fundamentación de su estudio en diversos trabajos académicos ${ }^{1}$. Recordemos un fragmento de su conocido artículo:

Pero de lo que quiero hablarles hoy es de música metal [...]. Esa música se divide en innumerables parcelas donde hay de todo: absurda bazofia analfabeta y composiciones dignas de estudio y respeto. Aunque parezca extraño y contradictorio, la palabra cultura no es ajena a una parte de ese mundo. Si uno acerca la oreja entre la maraña de voces confusas y guitarras atronadoras, a veces se tropieza con letras que abundan en referencias literarias, históricas, mitológicas y cinematográficas. Confieso que acabo de descubrir, asombrado, entre ese caos al que llamamos música metal, a grupos que han visto buen cine y leído buenos libros con pasión desaforada ${ }^{2}$.

En su enunciación, Pérez-Reverte se centra en las letras, texto en el cual residen las referencias culturales aludidas, desde el cine a la literatura. Nuestro trabajo atiende a otro plano de expresión de la canción popular, el texto sonoro, como elemento prioritario en el entramado intertextual de referencias que, en conjunción con el resto de textos -incluida la letra de las canciones-, favorece la articulación de significados culturales en el heavy metal en España. Nuestro reto es, por tanto, profundizar en lo que el escritor describe como la "maraña de voces confusas y guitarras atronadoras".

El presente artículo examina procesos inter/hipertextuales en torno al modo frigio, al intervalo de segunda menor y a la denominada supertónica descendida (también segundo grado rebajado o, de forma simplificada, b2) en la música metal en España. Se presentan una diversidad de representaciones de

\footnotetext{
${ }^{1}$ Algunas valoraciones sobre lo acertado de las palabras de Pérez Reverte en torno a la música metal se encuentran en Santiago Alfonso López Navia: "La recepción del Quijote en el rock español", Visiones del Quijote en la música del siglo XX, Begoña Lolo (coord.), Madrid, Centro de Estudios Cervantinos, 2010, pp. 683-696; Pablo Folgueira Lombardero: "La idea de historia en el heavy metal español", Tiempo y Sociedad, 3, 2010-2011, pp. 5-41.

2 Arturo Pérez Reverte: "Corsés góticos y cascos de walkiria", Patente de Corso, XL Semanal, 16-12-2007 (http://www.perezreverte.com/artículo/patentes-corso/177/corses-goticos-y-cascos-de-walkiria/, consulta 23-12-2014).
} 
esta estructura melódica y/o armónica, desde imaginarios sobre lo andaluz, español,árabe y flamenco en música, hasta su uso como marcador estilístico del metal sin evocaciones territoriales explícitas.Así, este elemento musical-acompañado de la idiomática distorsión-, incluido o excluido de la canción popular grabada de las bandas de metal, conforma un espacio en disputa para la reapropiación ideológica o, si se prefiere, una "batalla" -empleando el sociolecto característico del metal épico- por la enunciación de narrativas patrimoniales, la recreación de comunidades imaginadas y la construcción de discursos ambivalentes en torno a las identidades nacionales en España. En estos discursos y prácticas sonoras, la figura del héroe y lo heroico, habitual en las retóricas del heavy metal, lejos de quedar al margen de esta negociación de significados sobre la supertónica descendida, ejemplifica la diversidad -y distorsión- de significados en torno a lo nacional y sus narraciones.

Tomando en consideración referentes teórico-metodológicos que parten de la intertextualidad, nos centramos en el análisis e interpretación de la "canción popular grabada"”. En concreto, a lo largo de este artículo se emplea terminología analítica que parte de lo que Lacasse denomina "transfonografia", entendiendo esta como la clasificación de las referencias intertextuales e hipertextuales en el marco de la canción grabada ${ }^{4}$. Este musicólogo determina que, en el proceso de audición de una grabación, se pueden considerar tres conjuntos fundamentales, ya que "un fonograma fija y escenifica un conjunto de performances combinadas en torno a una composición ideal determinada" 5 . Por una parte, se encuentran los "parámetros abstractos", de tipo alográfico, referidos los aspectos estructurales de la pieza, desde la armonía a la línea melódica o la forma. Asimismo, Lacasse describe elementos vinculados a los "parámetros performativos" que han quedado registrados en la grabación -ya sean considerados como elementos contingentes de una canción ideal o constitutivos del evento efímero de carácter único que acarrea la performance-, desde un acento, una ornamentación, un timbre concreto o una entonación ligeramente desajustada en su perfil melódico - out of pitch - con respecto al armazón armónico, por ejemplo. En último lugar, entran en juego los "parámetros tecnológicos", vinculados a lo que este autor denomina "escenificación fonográfica", esto es, relativos a la producción musical, ya sea una distorsión del timbre, una reverberación, o a la mezcla, la edición y el ensamblaje de la grabación ${ }^{6}$.

\footnotetext{
${ }^{3}$ Allan F. Moore: Song Means: Analysing and Interpreting Recorded Popular Song, Surrey-Burlington, Ashgate, 2012.

${ }^{4}$ Serge Lacasse: "Toward a Model of Transphonography", The Pop Palimpsest: Intertextuality in Recorded Popular Song, Lori Burns, Serge Lacasse (eds.), Michigan, University of Michigan Press, 2018, pp. 9-60.

5 "A phonogram fixes and stages a set of combined performances of a given ideal composition" [traducción del autor], [cursivas en el original]. Ibid., p. 12.

${ }^{6}$ Ibid., pp. 11-12.
} 


\section{Ambivalencias de un signo musical}

El modo frigio y, más genéricamente, $b 2$-así como el tetracordio frigio descendente, estrechamente vinculado a la denominada "cadencia frigia" o "cadencia andaluza" - son marcadores estilísticos frecuentes en diferentes repertorios musicales vinculados a lo que ha venido a denominarse "música española". Esta, siguiendo a Llano, puede entenderse como un "proceso histórico y cultural de carácter dinámico que [...] abarca un conjunto de experiencias individuales y colectivas, así como agentes individuales e ins-

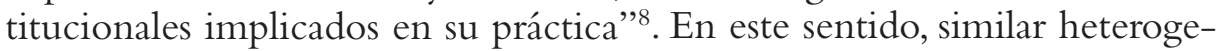
neidad presenta la idea de la "música andaluza", otra "realidad sonora polifónica, múltiple”, como afirman García Gallardo y Arredondo Pérez'. Así, en la música académica occidental, estos elementos musicales fueron cruciales para representar España en el marco del exotismo ${ }^{10}$ y el orientalismo por compositores tanto españoles como de otros países, especialmente desde el siglo XIX ${ }^{11}$.

${ }^{7}$ La teoría musical implica valoraciones de tipo ideológico, social y cultural en su descripción y uso del lenguaje, algo que afecta a la forma en la que se conciben las estructuras musicales. En el caso de la cadencia prototípica La-Sol-Fa-Mi en La (entendida como bIV-bIII-bII-I o i-bVII-bVI-V), esta ha sido descrita como "cadencia andaluza", así como "cadencia frigia", por sus reminiscencias y estructuras compartidas con el modo frigio. Sobre lo primero, véase Philip Tagg: "Music Theory Terminology as Ideology", 1st International Congress of Numanities (ICoN), Kaunas (Lithuania), 7-6-2014 (http://tagg.org/ html/Kaunas1406b.html, consulta 1-6-2019). Sobre la cadencia andaluza, véase Cristóbal L. García Gallardo: "La cadencia andaluza", Andalucía en la música. Expresión de comunidad, construcción de identidad, Francisco José García Gallardo, Herminia Arredondo Pérez (coords.), Sevilla, Centro de Estudios Andaluces, 2014, pp. 107-121.

8 "[...] a dynamic historical and cultural process that [...] encompasses a set of individual and collective experiences, as well as the personal and institutional agents engaged in their practice" [traducción del autor], Samuel Llano: Whose Spain? Negotiating "Spanish Music" in Paris, 1908-1929, Oxford, Oxford University Press, 2012, p. 237.

${ }^{9}$ F. J. García Gallardo, H. Arredondo Pérez: "Introducción. La música de Andalucía: Un jardín cultural, una comunidad imaginada", Andalucía en la música. Expresión de comunidad..., p. 14.

${ }^{10}$ A lo largo de este artículo empleamos la palabra "exotismo" en referencia a la construcción de una imagen estandarizada, estereotipada y relativamente "inmóvil" del Otro en términos culturales, sociales, políticos y musicales. Esta construcción es discursiva, por una parte, porque sus enunciadores -aquellos que realizan el acto de "exotizar" al Otro- articulan parte de su Yo en la descripción del otro y, por otra parte, el exotismo puede ser utilizado desde un punto de vista esencialista estratégico o colaboracionista con dicho estereotipo por parte del Otro.

${ }^{11}$ Véanse, entre otros, los trabajos de Ralph P. Locke: Musical Exoticism. Images and Reflections, New York, Cambridge University Press, 2009; R. P. Locke: "Spanish Local Color in Bizet's Carmen", Music, Theater, and Cultural Transfer: Paris, 1830-1914, Annegret Fauser, Mark Everist (eds.), Chicago, University of Chicago Press, 2009, pp. 316-360; Celsa Alonso: "En el espejo de 'los otros': andalucismo, exotismo e hispanismo", Creación musical, cultura popular y construcción nacional en la España contemporánea, Celsa Alonso et al., Madrid, ICCMU, 2010, pp. 83-103; S. Llano: Whose Spain? 
En el flamenco, como género híbrido y transcultural ${ }^{12}$ asociado con Andalucía y España, el b2 y el modo frigio constituyen sus principales marcadores estilísticos desde el puento de vista melódico-armónico ${ }^{13}$. Cabe destacar que, mientras el flamenco y diversas músicas tradicionales -o "músicas locales" 14 - andaluzas representan el ejemplo más evidente de empleo de este modo, repertorios musicales asociados a otros territorios dentro de España también recurren al modo frigio o el "modo de Mi", denominación habitual en los trabajos sobre música tradicional ${ }^{15}$. Similares consideraciones con respecto a la inclusión del b 2 pueden aplicarse a las músicas evocadoras de Al-Ándalus -entendiendo esta etiqueta como imaginario reinventado por comunidades y audiencias específicas ${ }^{16}$-, en las que estas escalas musicales e intervalos se emplean como elementos constitutivos de estilo $^{17}$.

Desde un punto de vista melódico, la supertónica descendida, vinculada al intervalo de segunda menor que caracteriza al modo frigio -y también al modo locrio, aunque está mucho menos presente en estas músicases uno de los elementos constitutivos de la sonoridad asociada al metal ${ }^{18}$. Según Cope, "la segunda menor ha sido adoptada constantemente en las

\footnotetext{
${ }^{12}$ Gerhard Steingress: "Flamenco Fusion and New Flamenco as Post-modern Phenomena: an Essay on Creative Ambiguity in Popular Music", Songs of the Minotaur: Hybridity and Popular Music in the Era of Globalization, Gerhard Steingress (ed.), Münster, Liv Verlag, 2002, pp. 169-216.

${ }^{13}$ Lola Fernández: Teoría musical del flamenco. Ritmo, armonía, melodía, forma, Madrid, Acordes Concert, 2004; Peter Manuel: "Modal Harmony in Andalusian, Eastern European, and Turkish Syncretic Musics", Yearbook for Traditional Music, 21, 1989, pp. 70-94.

${ }^{14}$ Siguiendo a Ana María Ochoa, pueden definirse como locales aquellas "músicas que en algún momento histórico estuvieron claramente asociadas a un territorio y a un grupo cultural o grupos culturales específicos -aun cuando la territorialización no haya sido necesariamente contenida en sus fronteras, y en las cuales esa territorialización original sigue jugando un papel en la definición genérica". Véase Ana María Ochoa: Músicas locales en tiempos de globalización, Buenos Aires, Norma, 2013, p. 11.

${ }^{15}$ David Fernández Durán: Sistemas de organización melódica en la música tradicional española, tesis doctoral, Universidad Complutense de Madrid, 2009, p. 107 (https://eprints.ucm.es/9597/1/T31073.pdf, consulta 7-11-2018).

${ }^{16}$ Jonathan Holt Shannon: Performing Al-Andalus: Music and Nostalgia across the Mediterranean, Bloomington, Indianápolis, Indiana University Press, 2015.

${ }^{17}$ Diego García-Peinazo: "Rock andaluz, orientalismos e identidad en la Andalucía de la Transición (1975-1982)", Musicología global, musicología local, Javier Marín López et al. (eds.), Madrid, Sociedad Española de Musicología, 2013, pp. 759-778; D. García-Peinazo: "Negotiating Andalusian Identity in Rock Andaluz Harmony. Musical Modes, 'Expressive Isomorphism' and Meaning in Post-Franco Spain", Speaking in Tongues. Pop Lokal Global, Dietrich Helms, Thomas Phleps (eds.), Bielefeld, Transcript, DeGruyter, 2015, pp. 141-156.

${ }^{18}$ Robert Walser: Running with the Devil: Power, Gender, and Madness in Heavy Metal Music, Middletown, Wesleyan University Press, 2013 (1993); Andrew Cope: Black Sabbath and the Rise of Heavy Metal Music, Surrey, Ashgate, 2010; Nicole Biamonte: "Les fonctions modales dans le rock et la musique metal", Lanalyse musicale aujourd'hui, M. Ayari; J.M. Bardez; X. Hascher (eds.), Strasbourg, University of Strasbourg, 2012; P. Tagg: Everyday Tonality II. Towards a Tonal Theory of what Most People Hear, New York/Huddersfield, The Mass Media Music Scholars' Press, 2014 (2009), (2. ${ }^{a}$ edición, ampliada y revisada); asimismo,
} 
bandas de heavy metal como elemento crucial en la composición de riffs de guitarra, llegado a ser un significante capital en la sintaxis del heavy metal"19. Empleándose de forma variada dentro de las frases de los riffs de guitarra, la inclusión de este intervalo en el metal se asocia fundamentalmente al modo frigio ${ }^{20}$.

Biamonte sugiere que, a pesar de que el modo frigio es frecuente en el heavy metal, este no es habitualmente "codificado" como "exótico" en estas músicas $^{21}$. Sin embargo, Moore sostiene que, en la música metal, la supertónica descendida puede ser entendida tanto como marcador estilístico (de la propia música metal) como representación de exotismo y orientalismo ${ }^{22} \mathrm{o}$ de género y sexualidad ${ }^{23}$, todo ello vinculado a la tensión y la disonancia:

La abundancia del $b 2$ en el heavy metal puede ser atribuible a sus connotaciones de tensión y transgresión heredadas de la música académica occidental, donde la inestabilidad de la disonancia del b2 es el Otro que se conduce hacia elYo de la tónica. Dentro de la música occidental representa generalmente la muerte, la fatalidad, la angustia o lo exótico. Estas asociaciones del b2 pueden convertirse en una herramienta poderosa en el heavy metal [...]. En el heavy metal, el motivo b2-1 es transformado en otro popular poderoso e impactante ${ }^{24}$.

Por tanto, el b2 puede articular una red de significaciones dentro de las bandas españolas de metal, en último término condicionadas por la "percepción ecológica"25. En la tipología del signo musical propuesta por Tagg, este musicólogo diferencia entre "indicadores de estilo" y "sinécdoques de

la b2 ha sido objeto de una tesis doctoral de Sarha Moore: The Other Leading Note: A Comparative Study of the Flat Second Pitch Degree in North Indian Classical, Ottoman or Arabian Influenced, Western, Heavy Metal and Film Musics, tesis doctoral, University of Sheffield, 2014.

19 "The flat 2nd has been consistently adopted by heavy metal bands as a key element in the writing of guitar riffs to become a major signifier of heavy metal syntax" [traducción del autor]. A. Cope: Black Sabbath ..., p. 124

${ }^{20} \mathrm{Ibid}$., p. 125.

${ }^{21}$ N. Biamonte: "Les fonctions modales...", p. 9.

22 S. Moore: "Dissonance and Dissidents: The Flattened Supertonic Within and Without of Heavy Metal Music", Heavy Fundametalisms: Music, Metal and Politics, Rosemary Hill, Karl Spracklen (eds.). Oxford, Inter-Disciplinary Press, 2010, pp. 127-141.

${ }^{23}$ S. Moore: "Metal, Machismo and Musical Mode: How the 'Feminine' Phrygian Second Has Been Appropriated and Transformed", Networking Knowledge: Journal of the MeCCSA Postgraduate Network 4, 1, 2011, (http://ojs.meccsa.org.uk/index.php/netknow/article/download/67/67, consulta 10-11-2018).

${ }^{24}$ The abundance of the $b 2$ in heavy metal may be attributable to its tense and transgressive connotations inherited from Western classical music, where the instability and dissonance of the b2 is the Other to the Self of the tonic. Within Western music generally it portrays doom, anguish, or the exotic. These very associations of the $b 2$ can make it powerful as a tool for heavy metal music [...]. In heavy metal, the b2 -1 motif is transformed into a popular Other that is powerful and shocking" [traducción del autor], en S. Moore: The Other Leading Note..., p. 210.

25 Véase Eric Clarke: Ways of Listening: An Ecological Approach to the Perception of Musical Meaning, Oxford, Oxford University Press, 2005. 
género musical". Los primeros son marcadores musicales que constituyen la identidad del "propio estilo", mientras que los segundos consisten fundamentalmente en la inclusión de elementos de un "estilo foráneo" en el marco del "estilo propio" 26 . Sin embargo, la dualidad intertextual de la supertónica descendida en el metal en España aglutina potencialmente estas dos perspectivas. Por una parte, este recurso expresivo musical puede operar como un indicador de estilo del propio metal -entiéndase, del metal a nivel internacional-. Por otra, también puede presentarse como una inclusión de otras músicas, desde el flamenco a comunidades sonoras imaginadas en torno a la idea de España y Andalucía, vinculadas a lo árabe y oriental, todas ellas sinécdoques de género, empleando el término de Tagg.

Por otra parte, Mynett ha destacado que la distorsión de acordes en la guitarra eléctrica, materializada a menudo en torno a power chords -esto es, acordes construidos en base a la fundamental, la quinta hueca y duplicación de la octava característicos del rock y el metal-, encarna la identidad última del sonido meta ${ }^{27}$. En este sentido, la supertónica descendida, como estructura vinculada a un indicador estilístico del metal, adquiere su significación plena cuando esta es planteada a través de la distorsión. No obstante, si bien el timbre -ya sea en términos de parámetro abstracto o de parámetro tecnológico- es un factor esencial en la conformación del metal, este no es siempre un auxilio para distinguir elementos de intertextualidad en la canción grabada de metal en España.

Philip Tagg sostiene, a través de diversos test de recepción auditiva basados en la teoría de la conmutación lingüística, cómo los cambios en el timbre de una estructura armónica, melódica o de la propia vocal persona pueden afectar a un determinado musema y, por tanto, a las connotaciones culturales de lo sonoro ${ }^{28}$. En el contexto sonoro del metal en España, sin embargo, desde una dimensión ecológica de la escucha, el timbre generado por la distorsión de guitarra eléctrica cuando se emplea la b2 es un indicio para determinar que estamos ante un marcador estilístico del metal, ante la evocación de lo andaluz, lo español, lo flamenco, lo árabe, etc. o ante ambas cosas. Por el contrario, aunque no sea la pretensión de este artículo, debemos tener presente otras problemáticas cuando una estructura armónica o

\footnotetext{
${ }^{26}$ Traduzco style indicators por "indicadores de estilo", genre synecdoches por "sinécdoques de género musical", home style por "estilo propio" y foreign style por "estilo foráneo". P. Tagg: Music’s Meanings. A Modern Musicology for non-Musos, Nueva York-Huddersfield, The Mass Media Music Scholars' Press, 2013, pp. 485-528.

${ }^{27}$ Mark Mynett: "The Distortion Paradox: Analyzing Contemporary Metal Production", Global Metal Music and Culture: Current Directions in Metal Studies, Andy R. Brown, Karl Spracklen, Keith Kahn-Harris, Niall W. R. Scott (eds.), Nueva York, Routledge, 2016, p. 68. Para un estudio sobre la generación de armónicos en torno a las quintas huecas de los power chords en el heavy metal, véase Esa Lilja: Theory and Analysis of Classic Heavy Metal Harmony, Vantaa, IAML Finland, 2009.

${ }^{28}$ P. Tagg: Music's Meanings..., p. 254.
} 
melódica de una canción de metal es interpretada mediante otros timbres -en un plano abstracto y de producción musical-y, por tanto, evidenciando la ausencia del timbre distorsionado de guitarra, como elemento vertebrador de este género musical.

\section{La supertónica descendida en el metal en España}

\section{El modo eólico y el b2: de los orígenes al power metal}

En su estudio sobre los primeros pasos del heavy metal a través de la banda Black Sabbath, Cope indica la profusión del modo eólico derivado del empleo de las escalas pentatónicas menores. Aunque el modo frigio no fuese siempre utilizado, subraya el énfasis del intervalo de segunda menor (siendo los dos primeros grados del modo frigio) que está en muchas canciones de Sabbath, y sostiene que la forma en la que esta banda jugó con la b2 en las estructuras eólicas fue decisiva para la construcción de un tipo de composición de riff que yuxtapone varios modos de forma libre ${ }^{29}$. A continuación, veremos cómo algunos ejemplos de la incorporación de la supertónica descendida en los repertorios de metal desde finales de los setenta en España se encuadran dentro de esta tendencia descrita por Cope en bandas como Black Sabbath.

Aunque diversas bandas españolas de hard rock desde la primera mitad de los setenta, como Eva-Rock, han sido consideradas pioneras del heavy metal en España ${ }^{30}$, la emergencia de este macro género se sitúa entre finales de los años setenta y mediados de los ochenta, con grupos como Barón Rojo, Obús o Muro, entre otros. Por su parte, factores como la inclusión frecuente del b2 en el contexto de estructuras melódicas y power chords con distorsión en modo frigio en las bandas de rock andaluz de los setenta ${ }^{31}$ han de ser considerados, al menos en términos de sintaxis musical, como vínculos entre las bandas de rock progresivo y las de heavy metal en España. Galicia Poblet ${ }^{32}$ demuestra que el modo eólico fue el modo más común en las bandas españolas de metal de los ochenta. Aun así, puede identificarse la supertónica en dos de las bandas seminales de los ochenta: Barón Rojo y Muro.

Una revisión de los siete álbumes que Barón Rojo publicó en esta década $^{33}$ evidencian que la presencia del b2 relacionado con el modo frigio es muy poco habitual. De las sesenta y cuatro piezas grabadas en estos

\footnotetext{
${ }^{29}$ A. Cope: Black Sabbath..., p. 126.

30 Salvador Domínguez: Bienvenido Mr. Rock. Los primeros grupos hispanos (1957-1975), Madrid, SGAE, 2002.

${ }^{31}$ D. García-Peinazo: "Negotiating Andalusian Identity...".

${ }^{32}$ Fernando Galicia Poblet: Inoxidable: Formación, cristalización y crecimiento del heavy metal en España (1978-1985), Madrid, Apache Libros, 2017.

${ }^{33}$ Larga vida al rock and roll, 1981; Volumen brutal, 1982; Metalmorfosis, 1983; En un lugar de la marcha, 1985; Tierra de Nadie, 1987; No va más, 1988; Obstinato, 1989.
} 
álbumes, tan solo "Las flores del mal" (Volumen brutal, 1982) emplea de forma recurrente el intervalo melódico de segunda menor (por ejemplo, en las estrofas y en el solo de guitarra), pero enmarcado dentro de la lógica del modo eólico (5-b6). Su estructura armónica está construida con un modo eólico en $\mathrm{Mi}$ en las estrofas, un modo eólico en La para el pre-chorus y un modo eólico en Si para el estribillo, lo que podría conceptualizarse dentro de lo que Guy Capuzzo denomina "tonalidad seccional"34.

Sin embargo, otras bandas españolas de la segunda mitad de los ochenta, como Muro, cercanas al trash metal y al speed metal, incluyeron la supertónica descendida a través del uso del modo frigio en sus canciones, lo cual es, siguiendo a Robert Walser, un recurso habitual en estos subestilos de metal $^{35}$. De las dieciséis canciones de los dos álbumes grabados por Muro en los ochenta, Acero y sangre, (1986) y Telón de acero $(1988)^{36}$, algunas de ellas utilizan profusamente el b2. Un caso significativo es "Juicio final" (Telón de acero), canción cuya letra describe una injusta condena a muerte. Si atendemos a la interacción entre el texto sonoro y la letra de la canción, este ejemplo operaría dentro del conjunto de asociaciones de la segunda menor con la fatalidad. En este sentido, la temática de la pena de muerte, que aparece en canciones como "Con mano izquierda" (2002) de la banda española de heavy metal Saratoga, recurre a estrategias modales similares en el perfil melódico de los versos de sus estrofas.

La supertónica descendida también ha sido usada por grupos de metal en España durante la década de los noventa y dos mil, períodos especialmente permeables a tendencias estilísticas como el power metal, pero con predominio del modo eólico y dórico. Sin embargo, el b 2 sigue apareciendo de manera persistente como marcador estilístico, ya se entienda como ornamentación dentro del modo eólico o como parte constitutiva del modo frigio. El grupo asturiano Avalanch, en sus tres primeros álbumes La llama eterna (1997), El llanto de un héroe (1999) y El ángel caído (2001)-, encuadrados dentro del power metal, utiliza diversas inclusiones de la supertónica descendida. Esta banda sigue la tendencia de presentar sus canciones en modo eólico, pero con la inflexión mediante el juego del cambio de la segunda mayor por la segunda menor del primer al segundo grado (1-b2), mediante riffs con distorsión. Siguen esta tendencia canciones como "El mundo perdido" (Llama eterna, 1997), en su riff inicial tras la introducción (0’50"-1'18”); “No pidas que crea en ti" (Llanto de un héroe,

\footnotetext{
${ }^{34}$ Guy Capuzzo: "Sectional Tonality and Sectional Centricity in Rock Music", Music Theory Spectrum, 31, 1, 2009, pp. 157-174.

${ }^{35}$ R. Walser: Running with the Devil..., p. 46

${ }^{36}$ No tenemos en consideración el álbum Mutant Hunter (1989) pues contiene solo versiones en inglés de canciones de la banda.
} 
1999) (0’58"-1'13"), o “Levántate y anda" (0’00"-0’15”) y “Las ruinas del Edén: Acto II" (0’37"-0'54"), del álbum El ángel caído (2001) ${ }^{37}$.

En el caso de "Fuego en la sangre" de la banda riojana Red Wine, se incorpora esta estructura en los interludios entre estrofas y estribillo (1'19"1'29"; 2'25"'-2'45”), así como en el solo de guitarra (3'22'-3'43”). La imitación del estilo metal funciona, por tanto, a la manera de un pastiche ${ }^{38}$, usando la b2 como marcador estilístico, dado que el contexto sonoro de esta canción está construido fundamentalmente en torno al modo eólico y jónico. Esta idea se refuerza, además, por la temática de la letra, que versa sobre la fuerza de la música heavy, la performance en directo del grupo y el encuentro con las audiencias.

\section{De marcador exótico a sinécdoque del género flamenco}

En otros grupos de metal, como Mägo de $\mathrm{Oz}$, tendentes al folk metal, aparece con profusión el modo dórico, empleado, a menudo, para recrear las evocaciones al imaginario de lo celta, así como los modos jónico, mixolidio y eólico. El uso del b2 en Mägo de Oz reviste un componente de exotismo y, a su vez, se vincula con la sexualidad y la pérdida de control por parte de elementos de oscuridad y fatalidad. Este hecho coincide con los enfoques descritos por Sarha Moore en su trabajo sobre género y b 2 en el metal internacional ${ }^{39}$.

En "Astaroth", canción perteneciente al álbum Finisterra (2000), la supertónica descendida es el hilo conductor de la canción, que incluye desde el inicio un característico patrón armónico frigio con power chords (I-b II-IbVII-I). Este está acompañado por el hook de la canción, una melodía en modo frigio interpretada por la flauta travesera y acompañada por el característico grito con proyección al agudo del heavy, también con ornamentación frigia. La letra, tendente a la metáfora y al doble sentido habitual en

${ }^{37}$ Nótese que, en Avalanch, estas estrategias armónicas suelen producirse con rápidas inflexiones entre la cuerda sexta al aire y su primer traste. Sin embargo, cabe destacar que esta banda afina la guitarra un semitono por debajo de la afinación estándar y, por tanto, suelen presentarse en la grabación en torno a un modo eólico en Mib -oscilación, por tanto, entre Mib-Fab-, en lugar de en un modo eólico en Mi.

38 Siguiendo a Ogas, en el pastiche "no se busca la cita, por lo tanto, lo importante no es tomar un material temático propuesto por otro compositor, sino que se busca adoptar o, si se quiere, llegar a dominar el estilo de ese otro compositor". J. Ogas: "El texto inacabado: tipologías intertextuales, música española y cultura", Creación musical..., p. 244.

${ }^{39}$ S. Moore: "Metal, Machismo and Musical Mode...". La trilogía discográfica Gaia, de Mägo de Oz, desarrolla un entramado intertextual en el cual se ponen en juego diversos referentes de tipo musical, histórico, político, literario y cinematográfico, entre otros. En D. García-Peinazo: "Intertextualidad y reapropiaciones musicales del Nuevo Mundo en la trilogía Gaia de Mägo de Oz: conquista, sexualidad y naturaleza en el heavy metal español", Síneris: Revista de Música, 30, 2017, pp. 1-36. Así, el grupo madrileño es un ejemplo de género fronterizo dentro del metal. Véase Silvia Martínez García: "Monstruos y fronteras en el heavy: un análisis desde lo híbrido", Nasarre. Revista Aragonesa de Musicología, 21, 1, 2005, pp. 31-45. 
Mägo de $\mathrm{Oz}$, parece vincularse, a partir de la idea demoniaca de Astaroth, a los deseos y sentimientos escondidos, reprimidos y ocultos del ser humano ("Ven hacia mí y déjame morar en ti; soy el deseo lo oscuro que hay en ti"). El componente de género y sexualidad se aprecia en "Astaroth" cuando, en la sección central de la canción, toma la palabra una cantante femenina invitada, que pide a dicho ser que la posea ("Tómame y el viento hará una canción, con el fuego eterno que sellará nuestra unión"). Aunque la letra no menciona ningún elemento orientalista explícito, es significativo que en algunas interpretaciones en directo de esta canción por parte de la banda aparezca una bailarina de danza del vientre en el escenario ${ }^{40}$, lo cual conecta el componente exótico, lo oriental y los estereotipos sobre lo femenino asociados a estos ${ }^{41}$.

Desde un punto de vista transfonográfico, también el tema de Mägo de Oz "Aquelarre" (Gaia II: La Voz Dormida, 2005) se encuentra emparentado con "Astaroth". El denominado "Príncipe del sexo y el dolor", personaje protagonista de la canción, de atributos demoníacos y vampíricos, de nuevo posee a una mujer. Por tanto, en primer lugar, nos encontramos ante un caso de interfonografía vinculado a la ficción de la letra ${ }^{42}$ : aunque Astaroth y el Príncipe de la dulce pena no sean exactamente el mismo personaje, comparten similares estereotipos de género y sexualidad -dominación y posesión sexual-, misticismo y esoterismo. En ambas canciones se produce, además, un diálogo entre un ser masculino - de tipo demoníaco en un caso y vampírico en el otro- iconizado por la voz del por entonces vocalista de Mägo de oz, José Andrea, y una mujer que es "poseída", representada en la voz de una mujer -Mar Cabello en el caso de "Astaroth" y Natalia Martín en "Aquelarre"-. Por otro lado, ambos temas comienzan con la profusión de la oscilación del patrón armónico frigio I-b II-I. Así, debido a la escasa presencia de esta estructura en la música de Mägo de Oz, puede entenderse como una alusión alosónica ${ }^{43}$.

En "Aquelarre", la supertónica descendida y la profusión del modo frigio se vinculan, además, a la evocación flamenca. Esto se produce, entre otros, por la incorporación de la guitarra flamenca de Moraito Chico y por la aparición de la voz de la cantaora de copla Diana Navarro en la coda de la canción, en la cual interpreta, con ayeos, el verso "Sedúceme, príncipe de la dulce pena". Aunque la confluencia entre flamenco y metal no pueda ser

${ }^{40}$ Véase "Astaroth", Live in Madrid, 2004 (https://www.youtube.com/watch?v=iYhHAal68zw, consulta 8-11-2018).

${ }^{41}$ Un estudio pionero sobre estas relaciones en música se encuentra en R. P Locke: "Constructing the Oriental 'Other': Saint-Saëns's 'Samson et Dalila”, Cambridge Opera Journal, 3, 3, 1991, pp. 261-302.

${ }^{42}$ Véase S. Lacasse: "Toward a Model of Transphonography...", p. 13.

${ }^{43}$ Ibid., p. 27. 
abordada aquí en profundidad por cuestiones de extensión ${ }^{44}$, cabe decir que la hibridación de ambos macrogéneros tiene su conexión principal en torno a esta estructura musical -por supuesto, no siempre vinculada al componente de exotismo y otredad latente en el caso de Mägo de $\mathrm{Oz}-$. Diversos grupos, desde los andaluces Fausto Taranto a la banda californiana Flametal, con el proyecto Heavy Mellow y, en especial, por el trabajo de su guitarrista Ben Woods, por citar dos ejemplos, han integrado de manera significativa el flamenco y la música metal. En el encuentro entre estos dos mundos de sentido se evidencia la centralidad de esta estructura como signo musical.

\section{¿Héroes frigios? Transfonografia, narrativas históricas e imaginarios épicos del metal en España}

En su estudio sobre la presencia de temáticas históricas en el heavy metal en España, Folgueira Lombardero destaca la recurrencia a las cruzadas y la Reconquista, así como la llegada de los españoles a América ${ }^{45}$, habiendo sido examinado esto último desde la perspectiva de la intertextualidad musical ${ }^{46}$. Así, predominan repertorios que profundizan tanto en el pasado histórico medieval español y, concretamente, en los conflictos bélicos entre cristianos y musulmanes en la Península como en personajes históricos, del Cid a Boabdil. En este sentido, si como apuntan K. Spracklen et al. ${ }^{47}$, el heavy metal proyecta narrativas patrimoniales como la recreación de los mitos históricos y héroes nacionales para la construcción de su identidad, se torna relevante abordar la manera en que la supertónica descendida opera dentro de estos discursos músico-culturales del metal estatal.

\section{Boabdil Metal Cry: Al-Ándalus como comunidad imaginada}

Al-Ándalus, como comunidad imaginada, ocupa un lugar prominente en diversas bandas de metal en España y, en concreto, en Andalucía. Paetzold, siguiendo a Cortés García y Alaoui, apunta que, en la cultura y sociedad andaluza actual, Al-Ándalus se convierte en un icono "asentado de manera profunda en la mitología y las historias legendarias, representando

${ }^{44}$ D. García-Peinazo: "Flamenco metal, mundos de género y transfonografía", Heavy-Y-Metal: A través del cristal. Nuevas perspectivas culturales, F. Galicia Poblet (ed.), Madrid, Apache, 2019, pp. 133-152.

${ }^{45}$ P. Folgueira Lombardero: "La idea de historia en el heavy metal español", Tiempo y Sociedad, 3, 20102011, pp. 5-41.

${ }^{46}$ D. García-Peinazo: "Intertextualidad y reapropiaciones...".

${ }^{47}$ K. Spracklen, C. Lucas, M. Deeks: "The Construction of Heavy Metal Identity through Heritage Narratives: A Case Study of Extreme Metal Bands in the North of England", Popular Music and Society, 37, 1, 2012, pp. 48-64. 
una época dorada y un paraíso perdido"48. Por su parte, Shannon otorga un papel importante a las prácticas musicales en la promoción de retóricas de lo que Amanda Lagerkvist denomina la "morada nostálgica", esto es, "maneras de habitar y articular experiencias vividas en espacios integrados por una marcada presencia del pasado"49.

Trabajos como los de Susan Martin-Márquez demuestran, desde enfoques de la teoría performativa, cómo la construcción de la identidad en España está estrechamente relacionada con una suerte de relaciones ambivalentes con el norte de África, especialmente con Marruecos, articuladas a lo largo de su historia ${ }^{50}$. En concreto, el legado Andalusí comienza a consolidarse como imaginario desde la Transición a la democracia, bajo la compleja noción de "convivencia", que desde los años noventa opera discursivamente en relación con la llegada a España de migraciones procedentes del norte de África y África Subsahariana ${ }^{51}$. Así, esta idea de "convivencia" ${ }^{2}$ ha sido resignificada y puesta en tela de juicio por parte de determinados sectores políticos a partir de transformaciones en España con la llegada del nuevo milenio, tales como la escalada de terrorismo vinculado al integrismo islámico, o la emergencia de discursos sobre la nación española que enuncian una visión negativa del "otro marroquí" 53 . Estas consideraciones ambivalentes sobre la lectura ideológica del pasado de Al-Ándalus y la significación "árabe” están presentes, como veremos, en diversas formaciones españolas de metal.

La evocación a estéticas orientalistas ya había sido una máxima en diversos grupos de rock andaluz de los setenta, tanto en los nombres de las formaciones -Imán Califato Independiente, Mezquita, Medina Azahara, Guadalquivir, etc.- como en los textos visuales, las letras de las canciones y, por supuesto, su música. Grupos como Taifa, Arábiga, Saurom o los propios Medina Azahara -única formación de rock andaluz de los años setenta que ha continuado su actividad de forma ininterrumpida- vuelven a recrear Al-Ándalus, esta vez desde el metal.

48 "Al-Andalus then becomes an icon [...] deeply embedded with mythology and fabled histories, representing a golden era and a lost paradise" [traducción del autor], Christopher Paetzold: "Singing beneath the Alhambra: The North African and Arabic Past and Present in Contemporary Andalusian Music", Journal of Spanish Cultural Studies, 10, 2, 2009, p. 208.

49 "...ways of inhabiting and articulating lived experience in places embedded with a heightened awareness of the past" (traducción del autor), A. Lagerkvist, 2013, citado en J. H. Shannon: Performing Al-Andalus: Music..., p. 8.

${ }^{50}$ Susan Martin-Márquez: Disorientations: Spanish Colonialism in Africa and the Performance of Identity, Yale, Yale University Press, 2008.

${ }^{51}$ Ibid., 307-316.

52 Sobre el concepto de "convivencia" en torno a Andalucía tras la muerte de Franco y a su resignificación a través de la figura de Blas Infante como padre de la Patria Andaluza, véase, entre otros, Eric Calderwood: "In Andalucia, There are No Foreigners': Andalucismo from Transperipheral Critique to Colonial Apology", Journal of Spanish Cultural Studies, 15, 4, 2014, pp. 399-417.

${ }^{53} \mathrm{Ibid} ., 317-318$. 
La banda Taifa, oriunda de las Islas Baleares, e influida por grupos internacionales de metal como Orphaned Land y estatales como Medina Azahara, evoca en sus discos las músicas del Magreb y del pasado de Al-Ándalus de manera constante. La supertónica descendida está presente, por ejemplo, en una parte importante de "Todo mi existir", canción integrada en el álbum Despertando el silencio (2012). La introducción instrumental, que emplea profusamente la distorsión de guitarra en esta estructura, recurre también a la inclusión de palmas que se panean a ambos lados del estéreo. Dichas palmas se emparentan, desde una perspectiva interfonográfica, con las estrategias seguidas para este instrumento de percusión corporal característico del flamenco en grupos de rock andaluz de los setenta como Mezquita - por ejemplo, la canción “Ara buza” (0'16"-0'35”), del álbum Recuerdos de mi tierra (1979) - o en "Omega” (7’30"-9'21”), tema del icónico álbum homónimo (1996) de Enrique Morente con Lagartija Nick. Por su parte, Arábiga, banda cordobesa de metal, grabó un disco, Reino de Taifas, en el cual el modo frigio es el eje vertebrador de algunos de sus temas, como "Reino de Taifas". Pero, de entre todas las formaciones de metal en España vinculadas a esta evocación orientalista, con toda probabilidad la que más presenta el modo frigio y la supertónica descendida es Medina Azahara. Esta banda cordobesa ha venido usando sistemáticamente estas estructuras musicales para caracterizar lo árabe en numerosos temas - desde "Favorita de un sultán" a "Danza de los velos", así como en los nombres de los propios discos ${ }^{54}$.

Boabdil, último rey de Granada, es otro ejemplo de elemento transfonográfico de tipo ficcional presente en el heavy metal en España. Once romances desde Al-Ándalus (2008), título de uno de los álbumes conceptuales del grupo gaditano Saurom, incluye en su última pista, "Sollozos desde el destierro", una alusión a Boabdil, empleando giros tendentes al modo frigio al comienzo de la misma, dado que se trata de una canción en la cual se combina la evocación del canto del muecín con el flamenco. Medina Azahara, en "Al pie de la Alhambra", ejemplifica con efectividad la mirada nostálgica a la temática de Boabdil, cuya intención no es celebratoria o heroica frente a la huida del "último rey moro de Granada", sino que es narrada en términos de pérdida:"Con pena y dolor, habló su madre a Boabdil". Destaca el uso del modo frigio y la oscilación entre el bII y el I en las estrofas, y de iv-bIII-bII-I, prototípica cadencia andaluza, para el estribillo: “Ay, Granada, la tierra soñada aún se escuchan llantos en el Albaicín” (letra Medina Azahara). Sin embargo, la lectura nostálgica para revisitar la figura de Boabdil no es exclusiva de las bandas andaluzas, como demuestra la letra de la canción "El último rey" del grupo madrileño Dark Moor: "Flor nazarí, yo te perdí/ y ahora me siento más andalusí; sueño la Alhambra, donde yo nací".

\footnotetext{
${ }^{54}$ Por ejemplo, En Al-Hakim (1989), Árabe (1995), Tánger (1998), Aixa (2003) o Al-Andalus (2012).
} 
En 1977, Los Puntos, grupo andaluz de pop procedente de Las Cuevas de Almanzora (Almería) grabó “Tierra cristiana” (álbum Oriental), también dedicada a Boabdil, cuya letra de nuevo se enmarca en la recreación nostálgica: "puedes oír decir su último adiós [...]. ¡Ay de mi raza de llanto bañada! ¡Ay de mi Sierra Nevada!" 55 . Otro de sus temas, "Llorando por Granada" (1977), también dedicado a Boabdil, fue grabado como cover en 2007 por José Luis Figuereo, conocido artísticamente como El Barrio. En la versión, el cantante abraza las estéticas sonoras del heavy metal, algo poco habitual en su discografia, aunque se considera seguidor del rock andaluz de grupos como Triana ${ }^{56}$.

Si la composición de Los Puntos de 1977 se situaba en un modo eólico - estrofas-y un modo mayor -estribillo-, lo significativo de la versión que plantea El Barrio es la incorporación de una introducción alternativa, ausente en la grabación original, en la cual se emplea el modo frigio. Dentro de la hiperfonografia que implica la versión, el añadido de esta introducción en modo frigio, no incluida en la grabación original, podría conceptualizarse como un tipo de "aumentación por extensión horizontal", en contraposición a la aumentación por extensión vertical que se serviría, por ejemplo, del añadido de voces o de bases rítmicas sobre una grabación dada ${ }^{57}$. En la versión de El Barrio se recurre, además, al timbre característico de los teclados empleados por el grupo Medina Azahara -el teclista de esta banda, Manuel Ibáñez, colaboró en la grabación del disco-, lo cual, a su vez, alude al rock andaluz como escena musical patrimonializada.

Tierra Santa es otra de las bandas de metal que ha revisitado a Boabdil, pero desde prismas diferentes a los anteriores ejemplos. Esta banda riojana, con claras influencias de la música de la New Wave of British Heavy Metal (NWBH) y, en concreto, de grupos como Iron Maiden, visita en sus textos temáticas históricas, con especial recurrencia a la Edad Media, como atestigua su primer disco Medieval (1997). Tierra Santa ha sido, en ocasiones, objeto de críticas por sus discursos en torno a la historia de España:

${ }^{55}$ La búsqueda de unas "raíces" intertextuales en torno a este personaje histórico podría llevarnos incluso hasta el romance ¿Qué es de ti, desconsolado?, compuesto por Juan del Encina (1468-1529).

${ }^{56}$ Figuereo reconoce estas influencias cuando afirma que le gusta el heavy, ya que "entre sus ídolos están nombres del metal como el guitarrista Petrucci", considerándose "deudor" del trío sevillano Triana. En "El Barrio: soy como un superhéroe que se disfraza y se convierte en artista", Agencia EFE, 4-11-2015 (https://www.efe.com/efe/espana/cultura/el-barrio-soy-como-un-superheroe-que-se-disfraza-y-convierteen-artista/10005-2754912, consulta 15-11-2018). Siguiendo la tipología de Lacasse, estos referentes serían de tipo parafonográfico y, en concreto, epitextos. S. Lacasse: "Toward a Model of Transphonography"..., p. 33.

${ }^{57}$ Lacasse describe diversos tipos de transformaciones cuantitativas que afectan a las dimensiones del fonograma. S. Lacasse: "Toward a Model of Transphonography"..., pp. 22-23. 
The Metal Circus: En muchos momentos se ha tildado a Tierra Santa de banda "patriótica", ya que habéis tratado ciertos aspectos de la historia de España en vuestras canciones [...].

Sergi Ramos, teclista Tierra Santa: Son cosas a las que nunca hemos hecho mucho caso. No entiendo como alguien puede llegar a pensar que tipos como nosotros están metidos en la derecha más radical y fascista ${ }^{58}$.

En la canción "Reconquista", correspondiente a su segundo álbum, Legendario (1999), Tierra Santa presenta una letra en la cual se canta:"Más de ocho siglos, intentando poder recuperar, una tierra que fue nuestra [...]. Tras mil batallas, acabó el reinado musulmán y esta tierra fue ya nuestra". En concreto, la mención a Boabdil se produce cuando se alude a la frase histórica atribuida a la madre de este, "Llora como mujer lo que no pudiste defender como hombre", presentada a capela por el vocalista de Tierra Santa con una ligera variación ("Lo que un día como hombre no supiste defender/ al dejar tu tierra lloras, como llora una mujer", 3’08"-3'30"). En términos armónicos, predominan los procesos cadenciales característicos del modo eólico en las músicas de hard rock y heavy metal (i-bVI-bVII-i) sin hallar rastro de la presencia del modo frigio. Frente a la "morada nostálgica" planteada en el ejemplo de Medina Azahara, en el caso de Tierra Santa se evidencia una otredad manifiesta frente a lo "árabe" en la narración del período histórico de la Reconquista".

\section{El Cid Campeador: paradojas sonoras de la exaltación nacional}

El Cid Campeador ha sido uno de los personajes históricos reiterados en los repertorios de metal en España. Los trabajos de Boix y Saguar han profundizado, desde la historia y la literatura, en la presencia de Rodrigo Díaz de Vivar en los repertorios de metal ${ }^{60}$. Es importante destacar, a este respecto, que ambos autores no se limitan al repertorio español, sino que incluyen canciones dedicadas al Cid por parte de bandas internacionales. En nuestro caso, sirviéndonos de la selección de canciones que ambos autores plantean, analizamos la dimensión musical que alcanza el Cid en relación con la supertónica descendida y el modo frigio, atendiendo a procesos transfonográficos, y cómo estos se vinculan, en ocasiones, con discursos ambivalentes sobre la identidad nacional en España.

${ }^{58}$ The Metal Circus, 4-5-2006 (https://www.themetalcircus.com/entrevistas/tierra-santa-no-se-como-alguien-puede-pensar-que-estamos-metidos-en-la-derecha-mas-radical-y-fascista/, consulta: 10-11-2018).

${ }^{59}$ Encontramos, en los repertorios de metal, otras canciones dedicadas a la Reconquista, como "Reconquista 1492" (Fifth Son of Winterdoom, 2013) del grupo belga Iron Mask.

${ }^{60}$ Alfonso Boix Jovaní: "Reflexiones en torno a la transmisión, pervivencia y evolución del mito cidiano en el heavy metal", Estudios de literatura medieval en la Península Ibérica, Carlos Alvar (coord.), San Millán de la Cogolla, Cilengua, 2015, pp. 303-315; Amaranta Saguar: "Presencia del Cid en el heavy metal en relación al auge y al declive de algunos de sus subgéneros", Monografías Aul@ Medieval, 6, 2017, pp. 75-90. 
Tras un análisis musical de las piezas vinculadas al Cid que Saguar propone en su artículo, las cuales combinan géneros que van desde el power metal al pagan metal, puede afirmarse que, en una parte importante de las mismas, no existe una presencia sustancial del modo frigio y la supertónica descendida en las canciones. Por ejemplo, no forma parte constitutiva del discurso musical de canciones como "Inmortal", de Xentria; "El Cid", del grupo Eagle the White; "El Cid the Champion", de Folkodia; "Leyenda y realidad", de Isengard; "Golpejar" (Parte I) de Heid; o "El Cid", de DragonHarp. Otras, sin embargo, sí incorporan el modo frigio como recurso expresivo. Tal es el caso de "El Cid", de Trauma, grupo costarricense que emplea dicho modo prácticamente en todo el tema. En "Leyenda y realidad", tema de la banda de Zamora Klangör, así como en "El Cid", de Pirámide $^{61}$ o en "Ruido de batalla", de Heid, predomina el modo eólico, incorporando la supertónica descendida en los interludios (2'38'-3'03"; 1'37"-2'48" y 1'12"-1'35", respectivamente). Especialmente en el caso del grupo Heid, se observa lo que Cope constata a propósito del juego del b2 dentro del modo eólico.

El estudio comparativo que desde la literatura y la historia realiza Boix sobre las visiones de El Cid Campeador en el metal se focaliza en canciones de grupos como Tierra Santa, Avalanch, Metallium, Dark Moor y Batallón de Castigo, entre otros. Su investigación se centra en dos cuestiones: 1) observar el grado de fidelidad de las letras con respecto a las fuentes primarias sobre el Cantar del Mío Cid; 2) examinar el grado de similitud o deformación ideológica que estas bandas de heavy proyectan sobre la historia del Cid. Así, determina tres tipos de aproximación por parte de los grupos: a) error de trasmisión, tomando como ejemplo "Revenge of Tizona" (2002), de Metalium; b) asunción de versiones populares de la leyenda, como en el caso de "Cid" (1999) de Avalanch,"Mío Cid" (2010) de Dark Moor y "Legendario" (1999), de Tierra Santa; c) Manipulación ideológica, focalizado en la canción "Campeador" (2004) del grupo Batallón de Castigo. Este autor considera que la visión selectiva que este último grupo hace sobre Rodrigo Díaz de Vivar "sigue de manera clara la imagen del Cid promulgada por el Franquismo como defensor de la patria, de ahí que el Campeador sea llamado 'Caudillo', apelativo con el que era conocido el Generalísimo Francisco Franco,

${ }^{61}$ Esta canción, aunque no está mencionada en los trabajos de Saguar y Boix, aparece en una lista de reproducción de Youtube titulada The Spanish Metal Ages. Esta incorpora la siguiente descripción general: "Recopilación con finalidad divulgativa. La inclusión en la lista no implica apoyo a la banda, ni ideológico ni material. No tenemos los derechos de ninguna de las canciones enlazadas". Véase (https://www.youtube. com/playlist?list=PLFxqzFPT7gIXFsuLxELvfqbrlgvDBNSLL, consulta 10-11-2018). En este sentido, entra en juego la tipología transfonográfica de la "archifonografía". Véase S. Lacasse: "Toward a Model of Transphonography...," pp. 16-18. 
utilizando el tópico del Cid 'Matamoros' para transmitir un mensaje acorde con la ideología neonazi" 62 .

En este sentido, Boix, desde el análisis histórico-literario, determina una parte relevante de los significados a la canción popular sobre el Cid. Para el autor fue muy importante el escrito de Reverte en el cual se hablaba de la "riqueza temática" del heavy metal, lo cual evidencia el impacto de este texto en los trabajos sobre heavy metal:

Este artículo fue un gesto importante en pro del heavy metal, tratando de demoler los tópicos habituales y mostrando la enorme riqueza cultural de las composiciones del género. Pero la oportunidad que ahora se presentaba ante mí era la de darle peso científico, de hacerlo objeto de estudio. No podía ir a lo fácil, al clásico enfoque pedagógico, el uso de las canciones en clases de inglés o para ilustrar de manera casi anecdótica una clase de historia o de literatura. Quería desarrollar algo que destacase la importancia de las canciones dedicadas al Cid en el heavy metal como obras valiosas en sí mismas ${ }^{63}$.

Pero ¿qué sucede en la "maraña de voces confusas y voces atronadoras"? Numerosos autores han reivindicado la importancia del texto sonoro de la canción popular como parte indisoluble del texto poético en la construcción de significados culturales, sociales y afectivos ${ }^{64}$. No se trata, tan solo, de lo que se canta, sino también de cómo se canta y lo que envuelve a esto o el "ambiente persónico" en la canción grabada, como lo denomina Allan F. Moore $^{65}$.

El hecho de analizar los elementos musicales que emplea el grupo Batallón de Castigo, de ideología franquista y nacionalcatólica, evidencia ambivalencias sonoras desde el punto de vista de la construcción y narración nacional en torno a la exaltación del héroe. "Campeador" utiliza, durante toda la canción, la supertónica descendida y el modo frigio. Recurre, además, tanto en los riffs de guitarra como en el perfil melódico de la voz, a la incorporación del tercer grado aumentado (Sol sostenido en un modo frigio en $\mathrm{Mi}$ ) con el tetracordio $\mathrm{Mi}-\mathrm{Fa}-\mathrm{Sol}$ sostenido-La de forma ascendente o descendente, lo que da por resultado una sonoridad muy cercana al denominado modo frigio dominante o modo hijaz, uno de los más icónicos indicadores de estilo de lo "árabe".

${ }^{62}$ A. Boix Jovaní: "Reflexiones en torno a la transmisión...", p. 307.

${ }^{63}$ R. Pérez Barredo: "El Cid, icono del heavy metal", Diario de Burgos, 25-10-2015, (http://www.diariodeburgos.es/noticia/Z1BA00B3E-C582-DFE2-655DB9A152300BE1/20151025/cid/icono/heavy/metal, consulta 13-11-2018).

${ }^{64}$ Véanse, Luiz Tatit,: "Analysing Popular Songs", Popular Music Studies, David Hesmondhalgh, Keith Negus (eds.), Londres, Arnold, 2002, pp. 33-50; y P. Tagg: Music's Meanings..., pp. 343-382.

${ }^{65}$ Traduzco por ambiente persónico, personic environment. A. F. Moore: "Una hermenéutica interrogativa de la canción popular", El Oído Pensante, 1, 1, 2013, pp. 1-21; A. F. Moore: Song Means... 
La ideología asentada en la retórica de la lucha contra lo que la banda considera el "invasor" convive paradójicamente con el uso de estas estructuras musicales del "Otro", que caracterizan la identidad sonora de este gru$\mathrm{po}^{66}$. En este sentido, son ilustradoras las palabras de Rubén López-Cano, quien sugiere que "[p]ara diferenciarnos de otra cultura o grupo, solemos construir escudos a partir de elementos de la misma civilización de la que queremos distinguirnos [...], la música destaca por la rapidez con que se deja reapropiar y por la eficaz manera que tiene de ocultar sus orígenes" ${ }^{67}$.

\section{Epílogo: la batalla por la supertónica descendida a las "Puertas de Babilonia"}

La canción "Gates of Babylon", con música de Ritchie Blackmore y Ronnie James Dio, fue publicada por la banda británica Rainbow en 1978 e incluida en el álbum Long Live Rock'n'Roll. El grupo se encuadra dentro del heavy metal y el hard rock, algo que se aprecia con nitidez en los recursos expresivo musicales empleados para la canción objeto de nuestro estudio. El carismático riff inicial (1-b2- \#3-b2-b7/ 1-b2- \$3-4-5/ 1-b2\#3-b2-b7/ b6-5-4-\#3-b2-1) está construido en torno a un modo frigio, pero incorpora el intervalo de segunda aumentada entre el segundo y el tercer grado ${ }^{68}$. Sobre la grabación de la canción, Jeff Perkins destaca su "maravillosa atmósfera evocadora de lo árabe [...], la pista se mueve a través de variadas emociones contando una historia perturbadora cargada de misterio y oscuridad" 69 .

Algunas versiones de esta canción, como las de Ozone (1994), Haaveiden Ilta (2010) o Age of Nemesis (2012), entre otras, siguen un patrón de afinidad bastante marcado tanto desde un punto de vista alográfico como performativo y de producción del riff en modo frigio. Se mantienen relativamente inalterados los parámetros de expresión musical y existen similitudes en cuanto a la armonía, melodía, tempo y cambios métricos, más allá de

\footnotetext{
${ }^{66}$ Sobre la representación y apropiación del Otro en música, véase, entre otros, Georgina Born, David Hesmondhalgh: "Introduction: On Difference, Representation, and Appropriation in Music", Western Music and Its Others: Difference, Representation, and Appropriation in Music, G. Born, D. Hesmondhalgh (eds.), Los Ángeles, University of California Press, 2000, pp. 1-58.

${ }^{67}$ Rubén López-Cano: Música Dispersa: Apropiación, influencias, robos y remix en la era de la escucha digital, Barcelona, Musikeon Books, 2018, p. 77.

${ }^{68}$ A este respecto, Robert Walser considera a Blackmore como el músico más destacado dentro de las primeras hibridaciones entre el metal y la música académica, siendo significativa la presencia de la música barroca en canciones como "Highway Star". En R. Walser: Running with the Devil..., pp. 64-65.

69 "Intensely eerie and driven along within a wonderfully evocative Arabian atmosphere [...] the track moves through varying emotional senses whilst telling a disturbing story full of mystery and darkness" (traducción del autor). J. Perkins: Rainbow: Uncensored on the Record. Warwickshire, Coda Books, 2011, p. 37.
} 
inclusiones puntuales de elementos diferenciados - por ejemplo, el uso del doble bombo en el caso de Age of Nemesis (en torno al 2'42"-2'54"), como refuerzo a través de este indicador estilístico del metal-.

La versión de Yngwie Malmsteen (2000) comienza con una introducción de sitar, lo cual potencia la idea del orientalismo vinculado al modo frigio de la canción y, por el uso de este instrumento, articula diversas miradas sobre lo "oriental". Incorpora, además, una ornamentación con un timbre de cuerda frotada con el perfil melódico 1-5-4-\$3-b2-b7 (en torno al 1'35'-1'37') que concuerda con la descripción anterior de la producción en términos de "evocadora atmósfera arabizante" de la "versión de referencia"70 de Rainbow. Algo similar sucede en la versión de "Gates of Babylon" que realiza el grupo andaluz Mezquita (2016), en la cual se incorpora, en el prechorus, una ornamentación "arabizante" en modo frigio que altera el perfil melódico de la canción compuesta por Blackmore y Dio (en torno al 1'37'-140"), lo que constituye, a su vez, una suerte de pastiche interfonográfico de canciones de Mezquita como "Desde que somos dos" (1979). Otros ejemplos, como "En nombre de Dios", cover por parte de la banda madrileña Mägo de $\mathrm{Oz}$, conservan recursos similares, aunque con cambios de tipo tímbrico, incorporando la flauta travesera como instrumento que doble el riff principal en modo frigio. A estos cambios habría que añadir, además, la adaptación de la letra del inglés al español, que en el caso de Mägo de $\mathrm{Oz}$ no es una traducción, aunque conecta lo frigio con la idea de la fatalidad y lo oscuro: la letra habla sobre vejaciones y abusos sexuales en el seno de la iglesia católica.

El caso de la versión de "Gates of Babylon", propuesta por el proyecto de Flametal Heavy Mellow (2010), liderado por el estadounidense Ben Woods, es quizás el más arriesgado de cara a la resignificación a través del cover. En primer lugar, se produce una transformación tímbrica, ya que toda la pieza está centrada en las guitarras flamencas, las palmas y el cajón. De la misma forma, se alteran los aspectos performativos de la grabación original: por ejemplo, en la introducción, con profusión de la supertónica descendida, frente a la oscilación melódica a través de glissandi provocados por la técnica del pitch bend en el sintetizador registrado en la grabación original. En la versión de Heavy Mellow, la introducción la realiza la guitarra flamenca, con recursos idiomáticos propios del flamenco, que se presentan a lo largo de todo el cover. Aunque, en el caso de dicha introducción, la guitarra flamenca está procesada con algo de reverb y de flanger -a fin de emular la sonoridad original-, el aspecto más destacado de esta versión es una ruptura decisiva

\footnotetext{
${ }^{70}$ Empleamos aquí el término "versión de referencia", en lugar de "versión original", siguiendo la propuesta de López-Cano. Véase R. López-Cano: "Lo original es la versión: covers, versiones y originales en la música popular urbana", ArtCultura: Uberlândia, 14, 24, 2012, p. 86.
} 
con lo que ha sido considerado como la identidad primaria del metal, es decir, con la distorsión, articulando un discurso musical que gira en torno a la recreación de dicha "distorsión ausente".

Manuel Martínez, vocalista de Medina Azahara sostiene que "si tú quitas mi voz de Medina Azahara, las canciones podrían ser cantadas por cualquier grupo de heavy del mundo"71. El cantante de esta histórica banda andaluza, al equiparar la música del grupo con los repertorios internacionales de heavy, ejemplifica esta ambivalencia de estructuras musicales como marcadores de estilo e indicadores identitarios. Así, el ambiente persónico que rodea la voz es compartido, en el marco de una disputa simbólica de elementos musicales en su encuentro con discursos ideológicos de diverso signo.

La supertónica descendida en el metal en España se erige como un signo musical continuamente reapropiado dentro de un entramado complejo de significados. El análisis de esta y de su principal modo "asociado", el modo frigio, reviste especial interés en España debido a su paradójica articulación de un amplio rango de representaciones ambivalentes, desde la exaltación nacional basada en figuras como el Cid hasta la evocación del pasado de Al-Ándalus, pasando por ser un marcador estilístico del metal sin tener que definir un contexto de exotismo o, por el contrario, una sinécdoque de género vinculada al flamenco, a lo andaluz o lo español en música. Nos sugiere, en definitiva, una suerte de batalla por la supertónica descendida en la cual la canción grabada de metal evidencia un espacio de negociación entre lo musical, lo cultural y lo político.

\footnotetext{
${ }^{71}$ Entrevista del autor a Manuel Martínez (Medina Azahara), Oviedo, 22-2-2013.
} 